\title{
Imagens do futebol na literatura alemã contemporânea
}

\author{
Images of football in the contemporary german literature
}

Elcio Loureiro Cornelsen

Universidade Federal de Minas Gerais (UFMG), Belo Horizonte / Brasil Doutor em Germanística pela Freie Universität Berlin emcor@uol.com.br

\begin{abstract}
RESUmo: Nossa contribuição visa a uma análise das imagens do futebol na literatura alemã contemporânea. Nesse intuito, elegemos as seguintes obras para comporem o corpus de análise: o conto Der Sonntag, an dem ich Weltmeister wurde (1994; O domingo em que me tornei campeão do mundo), de Friedrich Christian Delius, e o monólogo teatral Leben bis Männer (2001; Vivendo até se tornarem homens), de Thomas Brussig. Enquanto o conto de Delius retrata, ficcionalmente, a partir do olhar memorialista, a primeira conquista da seleção alemã em 1954, na Copa da Suíça, o longo monólogo teatral de Thomas Brussig apresenta uma única personagem, um treinador de futebol em fim de carreira, que treinava equipes infantis e infantojuvenis no passado, ainda na Alemanha Oriental.
\end{abstract}

PalAVRaS-CHAVE: Literatura alemã contemporânea; Imagens do futebol; Friedrich Christian Delius; Thomas Brussig.

ABSTRACT: Our contribution aims to analyze the images of football in the Contemporary German Literature. For this, we chose the following works to compose the corpus of analysis: Friedrich Christian Delius' tale Der Sonntag, an dem ich Weltmeister wurde (1994; The sunday I became world champion) and Thomas Brussig's theatrical monologue Leben bis Männer (2001; Living up to become men). While the tale of Delius portrays, fictionally, from memoirist look, the first conquest of the German national team in 1954, in the Swiss Cup, Brussig's long theatrical monologue presents a unique character, a football coach at the end of career that trained children and adolescents teams in the past, even in East Germany.

KEYwoRDS: Contemporary German Literature; Images of Football; Friedrich Christian Delius; Thomas Brussig. 


\section{INTRODUÇÃo}

Uma das potências do futebol mundial, a Alemanha, assim como o Brasil, tem no futebol a sua principal representação. Isso se reflete também no modo como essa modalidade esportiva passa a ser objeto de interesse nas produções literárias e artísticas.

Tal relação vai muito além do tema, pois, em 2005, foi fundada até mesmo uma "seleção alemã de escritores", a chamada Autonama - Autorennationalmannschaft. ${ }^{1}$ Parece que, por lá, a máxima de que "escritor não sabe nem bater escanteio" não funciona, pois a seleção de escritores alemães sagrou-se campeã europeia de 2010 em torneio disputado no país, que reuniu as seleções de escritores da Suécia, da Inglaterra, da Itália, da Hungria, da Áustria, e da Turquia, completado ainda por uma equipe de autores de romances policiais - a FC Criminale.

Nossa contribuição visa a uma análise das imagens do futebol na literatura alemã contemporânea. Nesse intuito, elegemos as seguintes obras para comporem o corpus de análise: o conto Der Sonntag, an dem ich Weltmeister wurde (O domingo em que me tornei campeão do mundo, 1994), de Friedrich Christian Delius, e o monólogo teatral Leben bis Männer (Vivendo até se tornarem homens, 2001), de Thomas Brussig. Enquanto o conto de Delius retrata, ficcionalmente, a partir do olhar memorialista, a primeira conquista da seleção alemã, em 1954, na Copa da Suíça, o longo monólogo teatral de Thomas Brussig apresenta uma única personagem, um treinador de futebol em fim de carreira, que treinava equipes infantis e infantojuvenis no passado, ainda na Alemanha Oriental.

\section{O “MILAGRE DE BERNA" E UM TORCEDOR ENTRE DEUS E O DIABO}

Quando o assunto é a relação entre futebol e literatura no contexto alemão, uma dessas produções que merece destaque é o conto $O$ domingo em que me tornei campeão do mundo (título original: Der Sonntag, an dem ich Weltmeister wurde), publicado pelo escritor alemão Friedrich Christian Delius em 1994. 0 referido

\footnotetext{
${ }^{1}$ Informações sobre a Autonama estão disponíveis em: <http://autonama.de/w2/>. Acesso em: 28 dez. 2015.
} 
conto - praticamente uma novela - retrata um momento significativo da história do futebol alemão, mais precisamente a primeira conquista da seleção alemã, em 1954, na Copa da Suíça, dando ensejo ao mito do famoso "Milagre de Berna". Basicamente, o conto é construído a partir do olhar memorialista de um adulto que narra sobre sua infância num lar protestante, sob uma educação rígida promovida por seu pai, que era pastor luterano - assim como o pai do próprio escritor.

Por assim dizer, esse narrador em primeira pessoa do singular estabelece uma perspectiva memorialista e se ocupa de sua infância e da educação rígida recebida no lar protestante. Com isso, a partida final da Copa da Suíça, disputada em Berna no dia 4 de julho de 1954, se torna o fio condutor para a narrativa. Enquanto ouve a transmissão de rádio da partida reunindo os selecionados da Alemanha e da Hungria, o garoto se confronta com vários temas, sobretudo com aspectos religiosos. Em certos momentos, o narrador-protagonista nutre até mesmo um sentimento de culpa, por considerar que o ato de ouvir futebol seria uma espécie de "profanação" do lar protestante.

o domingo em que me tornei campeão do mundo se destaca também pelo caráter intertextual, ao integrar passagens literais da narrativa da partida transmitida pelo rádio, na voz do então famoso locutor Herbert Zimmermann. A título de exemplo, elegemos a seguinte passagem do texto, em que o goleiro alemão Toni Turek faz uma grande defesa: nas palavras do locutor - "Turek, você é um sujeito do diabo! Turek, você é um deus do futebol!". ${ }^{2}$ E isso despertou os pensamentos do narrador-protagonista ao pé do rádio: “Eu me espantei com essas frases e, ao mesmo tempo, me alegrei, por Turek ter defendido, mas o espanto era mais profundo. [...]: uma nova forma de adoração, um culto depravado nunca visto, uma missa pagã, na qual se conclama, simultaneamente, a deus e ao diabo". ${ }^{3}$

Portanto, o narrador-protagonista espanta-se com os pensamentos e as palavras de cunho religioso proferidos por Herbert Zimmermann durante a

\footnotetext{
${ }^{2}$ DELIUS, Friedrich Christian. Der Sonntag, an dem ich Weltmeister wurde, p. 93. No original: "Turek, du bist ein Teufelskerl. Turek! du bist ein Fußsballgott!". Todas as traduções são de minha autoria.

${ }^{3}$ DELIUS. Der Sonntag, an dem ich Weltmeister wurde, p. 93. No original: "Ich erschrak mich über diese Sätze und freute mich gleichzeitig, daß Turek gehalten hatte, aber der Schrecken saß tiefer. [...] eine neue Form der Anbetung, ein lästerlicher, unerhörter Gottesdienst, eine heidnische Messe, in der einer gleichzeitig als Teufel und Gott angerufen wurde".
} 
FuLiA / UFMG - Imagens do futebol na literatura alemã contemporânea

transmissão da partida para expressar o júbilo e a emoção dos lances em favor da Seleção Alemã. Assim, aos olhos do adulto, que agora parece vivenciar o momento novamente como um garoto aos dez anos de idade, é como se estivesse cometendo um verdadeiro pecado. 0 sentimento de culpa leva-o até mesmo a mencionar os Mandamentos (Êxodo 20,1 e 7) como proteção contra a "heresia", mas percebe, ao mesmo tempo, que o "deus do futebol" - Fußballgott - assume o status de um ídolo humano, no caso, o goleiro Turek:

\begin{abstract}
Não terás outros deuses diante de mim. Não pronunciarás em vão o nome de Deus, mas me agradava, ainda tomado pelo eco da expressão 'deus do futebol', que esse deus era bem humano, que deuses, ao invés de estarem pendurados na cruz e sangrando, estavam protegendo o gol ou marcando gols por mim, se esfolavam na chuva torrencial e lutavam feito Liebrich, Liebrich, sempre, outra vez Liebrich, e aos poucos comecei a perceber porque meus pais não gostavam de futebol e do meu tímido interesse por esse esporte, talvez porque temessem a concorrência de outros deuses muito mais vivos. ${ }^{4}$
\end{abstract}

Ao longo de toda a transmissão radiofônica da partida, o protagonista vivencia o jogo com intensa paixão, associada à imaginação dos lances. Até mesmo seu corpo parece ganhar vida própria, fugindo-lhe do controle, como se o protagonista estivesse conectado com os jogadores no Wankdorf-Stadion de Berna. E, em meio a tanta excitação, ele tinha de manter o silêncio, para não quebrar a tranquilidade do domingo à tarde, ouvindo solitário a transmissão da partida no gabinete de seu pai, rodeado de estantes repletas de livros de teologia, “[...] onde sermões foram escritos, serviços religiosos foram realizados, onde foram dadas instruções a casais de noivos e a padrinhos de batismo [...]". ${ }^{5}$ Essa foi, aliás, a condição que o pai lhe impôs para que pudesse ouvir a transmissão da partida, mantendo estrito silêncio na casa.

\footnotetext{
${ }^{4}$ DELIUS. Der Sonntag, an dem ich Weltmeister wurde, p. 93-94. Grifos no original. No original: "[...] Du sollst keine anderen Götter haben neben mir, Du sollst den Namen des Herrn nicht unnützlich führen, und doch gefiel mir, noch immer gebannt vom Nachklang der drei Silben Fußballgott, daß dieser Gott sehr menschlich war, daß da Götter, statt blutend am Kreuz zu hängen, für mich im Tor standen oder Tore schossen, sich abrackerten im strömenden Regen und kämpften wie Liebrich, Liebrich, immer wieder Liebrich, und langsam ahnte ich, weshalb meine Eltern für den Fußball und für meine schüchterne Neigung zu diesem Sport nichts übrig hatten und hier vielleicht die Konkurrenz anderer, lebendigerer Götter fürchteten".

${ }^{5}$ DELIUS. Der Sonntag, an dem ich Weltmeister wurde, p. 94. No original: "[...] wo Predigten geschrieben, Andachten gehalten, Anweisungen an Brautpaaren und Taufpaten gegeben wurden".
} 
Todavia, conforme a partida avançava, crescia a emoção pela perspectiva de uma vitória histórica do selecionado alemão, emoção essa represada, conforme ilustra a seguinte passagem do conto, emoldurada pela transmissão de rádio:

[...] E a Alemanha ataca novamente... a voz suave e alta me elevou, me excitou para um novo sentimento, que me lançou, simultaneamente, numa paralisia silenciosa; eu sentia o caudal das emoções que o segundo gol havia despertado em mim, mas eu não tinha nenhuma válvula de escape para isso, não podia ter, de modo que represei tudo dentro de mim, coletei, armazenei e fiz silêncio. Crianças, isto é uma aflição! ${ }^{6}$

Ao final, pouco antes de a Alemanha marcar o terceiro gol, o narradorprotagonista dá mostras de que espera ansioso o fim da partida e de todo o sofrimento:

[...] ... seis minutos ainda, ninguém vacila, a chuva cai sem parar, é difícil, mas os espectadores resistem, quando é que a gente vai ver de novo uma final dessas, tão equilibrada, tão empolgante... Eu resistia, não suportava mais a tensão, o resultado me era quase indiferente, o mais importante era que os esforços sem limites do jogo logo acabariam... Schäfer cruza para o meio, a defesa tira de cabeça, vindo de trás Rahn devia chutar, Rahn chuta! Gol! Gol! Gol! Gol! Gol da Alemanha! ${ }^{7}$

A paixão pelo futebol é tratada ficcionalmente por Delius de uma forma muito rica, com muito sentimento para uma modalidade esportiva que fascina muita gente pelos quatro cantos do mundo. Ao final, o protagonista não tem dúvidas em afirmar: “[...] sem perceber, eu era o mais afortunado de todos, talvez mais afortunado do que Werner Liebrich ou Fritz Walter". ${ }^{8}$

\footnotetext{
${ }^{6}$ DELIUS. Der Sonntag, an dem ich Weltmeister wurde, p. 93. Grifos no original. No original: "[...] Und wieder stürmt Deutschland... die leise laute Stimme hob mich, peitschte mich zu einer Regung auf, die mich gleichzeitig in einen stimmlosen Stillstand versetzte, ich fühlte den Sturm der Gefühle, den das zweite Tor in mir ausgelöst hatte, aber ich hatte kein Ventil dafür, durfte keins haben, also staute ich alles auf, sammelte, speicherte und hielt still... Kinder, ist das eine Aufregung!".

${ }^{7}$ DELIUS. Der Sonntag, an dem ich Weltmeister wurde, p. 111. Grifos no original. No original: "[...] ... sechs Minuten noch, keiner wankt, der Regen prasselt unaufhörlich hernieder, es ist schwer, aber die Zuschauer, sie harren aus, wann sieht man ein solches Endspiel, so ausgeglichen, so packend... Ich harrte aus, ich ertrug die Spannung nicht mehr, das Ergebnis war mir fast egal, Hauptsache, die Strapazen des Spiels in ein paar Minuten vorbei... Schäfer, nach innen geflankt, Kopfball, abgewehrt, aus dem Hintergrund müßte Rahn schießen, Rahn schießt! Tor! Tor! Tor!Tor! Tor für Deutschland!".

${ }^{8}$ DELIUS. Der Sonntag, an dem ich Weltmeister wurde, p. 120. No original: "[...] war ich, ohne es zu begreifen, der glücklichste von allen, glücklicher vielleicht als Werner Liebrich oder Fritz Walter".
} 


\section{UM MONÓLOGO TEATRAL SOBRE FUTEBOL: VIVENDO ATÉ SE TORNAREM HOMENS}

No intuito de demonstrar que o futebol é objeto de interesse nas produções literárias e artísticas também na Alemanha, elegemos igualmente a obra Vivendo até se tornarem homens (2001; no original em alemão: Leben bis Männer), do escritor Thomas Brussig, um dos fundadores da Autonama, a equipe formada por escritores e outros integrantes do meio editorial. Esse autor berlinense, nascido em 19 de dezembro de 1964, um amante do futebol, escreveu, além da referida obra, outra que também tem por tema o futebol, intitulada Fertig, o árbitro (2007; no original: Schiedsrichter Fertig), designada pelo subtítulo de "Uma ladainha" (Eine Litanei).

Vivendo até se tornarem homens, um longo monólogo teatral, apresenta uma única personagem, um treinador de futebol em fim de carreira, que treinava equipes infantis, infantojuvenis e juvenis no passado, ainda nos tempos da Alemanha Oriental. E esse seria o sentido do título da obra: "Para meus jogadores, eu sempre tenho algo. Para formar um jogador desses, já é um feito e tanto. Crianças, meninos, escolares, juvenis, juniores - até se tornarem homens". ${ }^{9} \mathrm{Um}$ desses inúmeros garotos desempenha um papel importante na vida do treinador. Trata-se de Heiko, um garoto que passou a integrar a equipe do treinador quando contava nove anos de idade. Heiko jogava na defesa e era elogiado pelo treinador como um excelente jogador de cobertura, sempre muito obediente ao cumprir à risca as instruções de marcação: “[...] 0 Heiko chegou à equipe aos nove anos de idade, ainda menino. Desde então, eu o conheço. Totalmente confiável como jogador de cobertura. Quando eu lhe dizia 'marque o camisa 10', então, ele marcava. E o 10 não passava por ele de jeito nenhum".10

O treinador chega a se tornar uma espécie de figura paterna para Heiko, inicialmente movido pelo peso na consciência de ter prejudicado o garoto num

\footnotetext{
${ }^{9}$ BRUSSIG. Leben bis Männer, p. 85. No original: "Für meine Spieler hab ich was übrig. So einen Spieler aufzubauen, das ist schon was. Kinder, Knaben, Schüler, Jugend, Junioren - bis Männer". Todas as traduções são de minha autoria.

${ }^{10}$ BRUSSIG. Leben bis Männer, p. 85. No original: "[...] Der Heiko kam in die Mannschaft mit neun, also Knaben. So lange kenn ich den Heiko. Absolut zuverlässig als Manndecker. Wenn ich dem gesagt habe, bleib an dem Zehner dran - dann blieb der da auch dran. Und der Zehner kam nicht durch, um keinen Preis".
} 
FuLiA / UFMG - Imagens do futebol na literatura alemã contemporânea

jogo antes de Heiko vir para o seu time. Numa partida entre duas equipes infantis, o treinador, ardilosamente, gritou da linha para o jogador do time adversário, que marcava seu ataque, dizendo que o cadarço dele estava desamarrado. Num instante de distração, o time do treinador atacou e marcou o gol da vitória. Assim, Heiko perdeu sua posição no time adversário e foi "adotado" pelo treinador:

Aquele era o Heiko, com os tênis. Naquela época, estava com nove anos. Quando quis amarrar os tênis, os meus fizeram um gol. Heiko chorou. Claro que eu senti - quando um adulto diz algo a um garoto de nove anos, eles não podem distinguir isso. 0 treinador de Heiko gritou com ele: Você é uma menina ou por que tá choramingando? Foi quando consolei o Heiko. Afinal, não sou nenhum monstro. ${ }^{11}$

Todavia, para além do tema do futebol, essa obra de Thomas Brussig aborda também questões comportamentais associadas a posturas políticas. 0 treinador é uma figura autoritária, que exigia de seus comandados, e em especial de Heiko, a mais estrita obediência, a ponto de pedir para ele "entrar para quebrar" (umhauen), chegando a provocar sua expulsão:

[...] Certa vez, eu acho que era ainda na categoria escolar, quando Heiko era escolar, um jogador corria livre em direção ao gol vazio, tinha passado pela defesa. Então, pensei berra Quebra! em tom normal E o Heiko o quebrou. Recebeu cartão vermelho, óbvio - mas eu pensei: assim é o Heiko. Uma alma fiel. ${ }^{12}$

E esse tipo de comportamento do menino teria sérias consequências em sua fase adulta. 0 próprio treinador definia seu modo de atuar diante dos comandados como o de uma figura autoritária: “Eu sou do tipo que berra em campo, apesar de

${ }^{11}$ BRUSSIG. Leben bis Männer, p. 12-13. No original: "Das war der Heiko, der mit den Schuhen. Neun war er damals. Als der sich die Schuhe zuschnürte, machten meine ein Tor. Hat der Heiko geweint. Da tats mir natürlich leid - wenn ein Erwachsener was zu nem Neunjährigen sagt, die können das nicht unterscheiden. Der Trainer von Heiko hat ihn angefaucht: Bist du n Mädchen, oder warum flennste! Da hab ich den Heiko getröstet. Bin doch kein Unmensch".

${ }^{12}$ BRUSSIG. Leben bis Männer, p. 85. No original: "Einmal, ich glaub, es war Schüler, also Heiko Schüler war, da lief einer allein aufs leere Tor zu, war durch. Hab ich gedacht brüllt Haun um! normal Und Heiko hatn umgehaun. Gab Rot, klar - aber ich dachte, so ist der Heiko. Ne treue Seele". 
que eu não berro, eu penso, penso com paixão, penso e comando. 0 estrategista na beira do gramado. 0 Júlio César da linha lateral. ".13

Mais tarde, quando o jovem já figurava como capitão da equipe de juvenis, ele foi convocado para o serviço militar obrigatório e se tornou suboficial do Exército Nacional Popular (Nationale Volksarmee). Heiko passou a integrar as tropas responsáveis pela segurança das áreas de fronteira entre os Estados alemães. Numa de suas missões, ele atirou contra alguém que tentava fugir da Alemanha Oriental através da fronteira, matando-o. A expressão que Heiko empregou para definir o ato é a mesma que o treinador empregava para uma marcação dura e cerrada (umhauen):

[...] 1988, durante a Copa Europa de Seleções, assistimos juntos a alguns jogos. Quando os holandeses ainda deram uma lição nos alemães ocidentais. Foi quando o Heiko estava sentado no sofá lá de casa. Tinha recebido uma licença especial [do Exército]. No momento em que o Jürgen Kohler deu uma entrada no van Basten, ele me disse: Treinador, eu quebrei um. Eu já tinha imaginado isso. Afinal, não havia lá muitos motivos para uma licença especial. ${ }^{14}$

Após a Queda do Muro de Berlim e a Reunificação da Alemanha, Heiko foi levado a julgamento e condenado a dois anos de reclusão pelo assassinato cometido enquanto atuava como guarda de fronteira, momento que o treinador assim definiu: "A merda toda só começou quando o Muro caiu. Para o Heiko, foi com a Queda do Muro... [...]". ${ }^{15}$ Assim, Heiko, que, desde pequeno, fora educado pelo treinador a obedecer cegamente a suas instruções, teria seguido à risca as ordens do comando militar na fronteira entre as Alemanhas, não hesitando em atirar e matar um fugitivo.

Ao final do longo monólogo, predomina um tom irônico, em que o círculo se fecha: novos garotos chegam para o treinamento, e o treinador parece não ter

\footnotetext{
${ }^{13}$ BRUSSIG. Leben bis Männer, p. 12. No original: "Ich bin ein Platzbrüller, obwohl ich nicht brülle, sondern denke, leidenschaftlich denke, denke und lenke. Der Stratege am Rand. Der Jiulius Cäsar der Seitenlinie".

${ }^{14}$ BRUSSIG. Leben bis Männer, p. 88. No original em alemão: "[...] Achtundachtizg, zur EM, haben wir zusammen ein paar Spiele gesehen. Als die Holländer den Westen noch mal so richtig aufmischten. Da hat der Heiko bei mir zu Hause aufm Sofa gesessen. Hatte Sonderurlaub. Und wie der Jürgen Kohler den van Basten von den Beinen holte, hat er mir gesagt: Trainer, ich habe einen umgehaun. Das hatte ich mir schon gedacht. Gab ja nicht viele Gründe für Sonderurlaub".

${ }^{15}$ BRUSSIG. Leben bis Männer, p. 89. No original em alemão: "Die ganze Scheiße fing erst an, als die Mauer gefallen war. Für Heiko war das mit dem Mauerfall...[...]".
} 
aprendido nada com o ocorrido no passado. Sua postura autoritária permanece inalterada. Estas são suas primeiras palavras aos novos comandados mirins: "Homens! Futebol é tudo!"16

\section{FUTEBOL ENTRE DEUS E O DIABO, OU O ESTADO - À GUISA DE CONCLUSÃo}

Nosso breve estudo nos permite, ao final, tecer algumas conjecturas no sentido de relacionar as duas obras. Se o protagonista do conto $O$ domingo em que me tornei campeão do mundo, ainda garoto, descobre no torcer uma nova "comunidade imaginada",17 em que precisa romper com a educação e os valores em um lar religioso, deixando de ver o futebol como algo do "diabo", o protagonista do monólogo teatral Vivendo até se tornarem homens, marcado por vários preconceitos e mantendo uma postura autoritária, parece se ressentir pela falta do Estado socialista da República Democrática Alemã (RDA). Se, para este, Heiko só foi condenado à prisão porque a RDA e sua ordem autoritária chegaram ao fim com a Queda do Muro e a Reunificação, para o jovem torcedor, o ato de torcer pela Seleção Alemã na final da Copa de 1954 foi uma espécie de iniciação em uma nova vida.

Interessante nessa aproximação entre as obras é perceber que, além de veicularem perspectivas distintas em relação a aspectos geopolíticos - o torcer pela Seleção da Alemanha Ocidental; o cumprimento de ordens num Estado totalitário como a Alemanha Ocidental -, em O domingo em que me tornei campeão do mundo há um tom edificante, integrado ao momento do "milagre econômico" numa Alemanha do pós-guerra que tentava se reerguer. Já em Vivendo até se tornarem homens, não há uma mudança na postura do protagonista, de modo que o monólogo se torna circular; além de um tom pessimista em relação à sociedade alemã pós-Reunificação, nota-se nessa continuidade traços comportamentais dos tempos de outrora na RDA. E ambos os autores, Delius e Brussig, cada um a sua maneira, se valem do tema do futebol para ir além e pensar questões existenciais e sociopolíticas em dois momentos importantes da história da Alemanha.

\footnotetext{
${ }^{16}$ BRUSSIG. Leben bis Männer, p. 96. No original: "Männer! Fußball ist alles!".

${ }^{17}$ ANDERSON. Comunidades imaginadas, p. 19.
} 


\section{REFERÊNCIAS:}

ANDERSON, Benedict. Comunidades imaginadas: reflexões sobre a origem e a difusão do nacionalismo. 3. reimp., trad. Denise Bottman, São Paulo: Companhia das Letras, 2008.

BRUSSIG, Thomas. Leben bis Männer. Frankfurt a.M.: Fischer, 2001. DELIUS, Friedrich Christian. Der Sonntag, an dem ich Weltmeister wurde. Reinbek bei Hamburg: Rowohlt, 1994.

Autonama. Disponível em: <http://autonama.de/w2/>. Acesso em: $28 \mathrm{dez}$. 2015. 